Global Conferences Series:

Social Sciences, Education and Humanities (GCSSSEH), Volume 3, 2019

The $1^{\text {st }}$ International Conference on Education, Social Sciences and Humanities

DOI: https://doi.org/10.326/hum0223

\title{
Profile Children with Spastic Cerebral Palsy and Preparing Services Program in Special School
}

\author{
Riksma Akhlan ${ }^{1}$, Sunaryo Kartadinata ${ }^{2}$, Endang Rochyadi ${ }^{3}$, Hamidie Ronald ${ }^{4}$ \\ 1,23,4 Unversitas Pendidikan Indonesia, Bandung, Indonesia, \\ (*) $\square$ riksma_akhlan@upi.edu
}

\begin{abstract}
Parts of motor development have an important role in the life and development of children, referred as movement abilities throughout the lifetime. Students with spastic cerebral palsy have spesific characteristics when their moving, the spastic muscle and rigidity, poor posture control are inhibiting factors in achieving functional movements. Qualitative research approach through interviews with parents and standard assessment tests on body awareness using BARS, RTc and posture, control posture sitting assess by PPAS and Gross Motor by GMFCS-R. The results of BARS, RTc and PPAS measurements in 4 spastic cerebral palsy students, show poor body awareness, release tension, the quality and quantity posture control data also show the similar result from front and side of sitting posture. Body awareness and posture control are preequisit factors for the quality of functional movements, profile of the student contain the strength and abilities, weakness and the needed of the student for services program. Development is a cumulative process, meaning that obstacles to previous developments will hamper further development, further research needs to be done in relation to body awareness and the release tension that occurs during movement
\end{abstract}

Keywords: cerebral palsy spastic, body awareness, release tension, sitting control postur, services program.

\section{Introduction}

Cerebral palsy according to Swaiman and $\mathrm{Wu}$ (2012) is a brain disorder that is associated with movement and posture that causes abnormalities, affects muscle tone (from floppy to stiff) and abnormal posture (body and limb position), looks more like childhood with mild to severe ranges. Development as a systematic change and continuity in individuals that occurs between conception and death, or from the womb to the tomb (Sigelman and Shaffer, 1995, p. 2). Puckett and Black (2007) explain the motor development of each child will be different, the development milestone that emerges is the average development in each child, which is used to see whether a child has an average or possible achievement, can be adjusted to the child. Knowing the profile of motor skills in body awareness, release tension and controlling the posture of spastic cerebral palsy students with the preparation of service programs, this data becomes an urgency for students whose activities are carried out mostly in sitting position, or can stand and walk but not show in the best quantity of time, students have a sitting posture that is unstable and in the elementary school level. The 
assessment of spastic cerebral palsy students needs to be revealed as a first step to ensure the same data in every need for service program.

\section{Method}

The profile assessment of the children who participated in the study was obtained from parents' interviews, assessments conducted by the teacher using assessment of Body Awareness Rating Scale (BARS) to determine body awareness abilities, Release Tension checklist (RTchecklit) to determine the ability to release tension and Posture and Postural Ability Scale (PPAS) to determine posture and control of sitting posture from the front and side view. Data on children's ability to mobilisation use Gross Motor Functional Classification System - Expanded and Revised (GMFCS-E \& R) and doctor's diagnosis as validation. The study was conducted on 4 special school students in Bandung at the beginning of the semester, aged 6-12 years

\section{Results and Discussion}

Results of measurements Data found in the profile of spastic cerebral palsy students with ambulation ability, standing, walking very low were seen from GMFCS-R Level II, IV and V. Body awareness assessment used Body Awareness Rating Scale (BARS) find 1 student at level 3 means the quality of weak functional movements, 2 students at level 4 means the quality of functional movements is poor, 1 student at level 5 means functional movement is fair, when the student has a bigger score the more functional the movement, maximum score 7 . Release tension score not more than 3, unable to release tension. Release tension checklist for 1 student is at capable at passive movement, ability to increase and lower tension of the muscle, joint and nerve, 2 student only has passive movement ability, 1 student has no capability of release tension at all. Posture control in quantity variation from 2 to 7, quality of sitting position from front and side view at level 1 to 6 .

Table 1. Body Awareness Rating Scale Score (BARS)

\begin{tabular}{clccccc}
\hline \multirow{2}{*}{ No } & \multirow{2}{*}{ Aspect } & \multicolumn{4}{c}{ Level } \\
\cline { 3 - 6 } & & D & Ay & Ag & In \\
\hline 1. & Vertical axis & 5 & 3 & 4 & 4 \\
\hline 2. & Movement characteristics & 5 & 3 & 4 & 4 \\
\hline 3. & Amount of energy in the movement & 5 & 3 & 4 & 4 \\
\hline 4. & Ability to move with purpose & 5 & 3 & 4 & 4 \\
\hline $5 . \quad$ Movement harmony & 5 & 3 & 4 & 4 \\
\hline quality functional movement weak, $4=$ quality functional movement poor, $5=$ quality functional movement fair. & & & &
\end{tabular}

Table 2. Body Awareness Assessment (Parents Interview)

\begin{tabular}{clcccc}
\hline \multirow{2}{*}{ No } & \multicolumn{1}{c}{ Body Awareness } & \multicolumn{4}{c}{ Score } \\
\cline { 3 - 6 } & & D & Ay & Ag & In \\
\hline 1 & Vertical axis: & 1 & 1 & 1 & 1 \\
& Head control motion & 0 & 1 & 1 & 0 \\
\hline 2 & $\begin{array}{l}\text { Movement characteristics } \\
\text { Body movement : hands, feet and body }\end{array}$ & 0 & 0 & 0 & 0 \\
\hline 3 & $\begin{array}{l}\text { Amount of energy in the movement } \\
\text { Respiratory motion: chest -abdominal breathing }\end{array}$ & 0 & 0 & 0 & 0 \\
\hline 4 & $\begin{array}{l}\text { Ability to move with purpose } \\
\text { a. Move bodily }\end{array}$ & & & & \\
\hline & b. Move mobility aid & 1 & 1 & 1 & 1 \\
\hline 5 & $\begin{array}{l}\text { Movement harmony } \\
\text { a. Gross motor coordination }\end{array}$ & 1 & 1 & 1 & 1 \\
\hline & b. Fine motor coordination & 1 & 1 & 1 & 1 \\
\hline
\end{tabular}




\begin{tabular}{|c|c|c|c|c|c|}
\hline c. Eye-hand coordination & & 1 & 1 & 1 & 1 \\
\hline d. Eye-foot coordination & & 1 & 1 & 1 & 1 \\
\hline & Total & 7 & 8 & 8 & 7 \\
\hline
\end{tabular}

Table 3. Release Tension Checklist

\begin{tabular}{|c|c|c|c|c|c|}
\hline \multirow{2}{*}{ No } & \multirow{2}{*}{ Release Tension Ability } & \multicolumn{4}{|c|}{ Scors } \\
\hline & & $\mathbf{D}$ & Ay & $\mathrm{Ag}$ & In \\
\hline 1 & $\begin{array}{l}\text { Passive movement : do not have the ability or strength of muscle } \\
\text { and joints }\end{array}$ & 1 & 1 & 0 & 1 \\
\hline 2 & Active movement : optimizing muscle and joint movement & 0 & 0 & 0 & 0 \\
\hline 3 & Knowledge of muscles, joints and nerves strength & 0 & 0 & 0 & 0 \\
\hline 4 & Knowledge of spastic muscle and joints & 0 & 0 & 0 & 0 \\
\hline 5 & $\begin{array}{l}\text { Express muscle movement harmony, balance so the moves } \\
\text { according to function }\end{array}$ & 0 & 0 & 0 & 0 \\
\hline 6 & $\begin{array}{l}\text { Ability to increase the strength of muscles, joints, nerves in } \\
\text { limbs/extremities }\end{array}$ & 1 & 0 & 0 & 0 \\
\hline 7 & $\begin{array}{l}\text { Ability to reduce the strength of muscles, joints, nerves in } \\
\text { limbs/extremities }\end{array}$ & 1 & 0 & 0 & 0 \\
\hline 8 & Senso motor ability in spastic muscle & 0 & 0 & 0 & 0 \\
\hline 9 & Ability of limbs who difficult moved to function optimally & 0 & 0 & 0 & 0 \\
\hline 10 & Ability to regulate energy according release of stiffness & 0 & 0 & 0 & 0 \\
\hline & Total & 3 & 1 & 0 & 1 \\
\hline
\end{tabular}

Table 4. Asessment Postur Quality Front and Side View(PPAS)

\begin{tabular}{|c|c|c|c|c|c|c|c|c|c|}
\hline \multirow{2}{*}{ Frontal } & \multicolumn{4}{|c|}{ Scores } & \multirow{2}{*}{ Sagital } & \multicolumn{4}{|c|}{ Scores } \\
\hline & D & Ay & Ag & In & & D & Ay & Ag & In \\
\hline Head midline & 1 & 0 & 0 & 1 & Head midline & 0 & 0 & 0 & 0 \\
\hline Trunk symmetrical & 1 & 0 & 0 & 1 & $\begin{array}{l}\text { Tunk in neutral } \\
\text { position }\end{array}$ & 1 & 1 & 0 & 1 \\
\hline Pelvis neutral & 1 & 1 & 0 & 1 & Pelvis neutral & 1 & 0 & 1 & 0 \\
\hline $\begin{array}{l}\text { Legs separated and } \\
\text { straight relative to } \\
\text { pelvis }\end{array}$ & 1 & 1 & 0 & 1 & $\begin{array}{l}\text { Hips mid-position } \\
\left(90^{\circ}\right)\end{array}$ & 1 & 1 & 0 & 0 \\
\hline Arms resting by side & 1 & 1 & 1 & 1 & $\begin{array}{l}\text { Knees mid-position } \\
\left(90^{\circ}\right)\end{array}$ & 0 & 1 & 1 & 0 \\
\hline $\begin{array}{l}\text { Weight evenly } \\
\text { distributed }\end{array}$ & 1 & 0 & 0 & 1 & $\begin{array}{l}\text { Feet mid-position/flat } \\
\text { on floor }\end{array}$ & 0 & 0 & 0 & 0 \\
\hline Total score & 6 & 3 & 1 & 6 & & 3 & 3 & 2 & 1 \\
\hline $\begin{array}{l}\text { Score of quality: } \\
\text { Maximum scores: }\end{array}$ & & & & & $\begin{array}{l}0=\text { no } \\
\text { Frontal: } 6\end{array}$ & & & & \\
\hline
\end{tabular}


Table 5. Quality of posture and Quantity level of postural ability in sitting

\begin{tabular}{|c|c|c|c|c|c|c|}
\hline \multirow{2}{*}{ No } & \multirow{2}{*}{\multicolumn{2}{|c|}{ Pernyataan }} & \multicolumn{4}{|c|}{ Level } \\
\hline & & & D & Ay & Ag & In \\
\hline 1. & \multicolumn{2}{|r|}{ Quality of posture in sitting frontal } & 6 & 3 & 1 & 6 \\
\hline 2. & \multicolumn{2}{|c|}{ Quality of posture in sitting sagital } & 3 & 3 & 2 & 1 \\
\hline 3. & \multicolumn{2}{|r|}{ Quantity level of postural ability in sitting: } & 7 & 2 & 2 & 4 \\
\hline \multicolumn{2}{|c|}{ Level 1} & \multicolumn{5}{|l|}{ Unplaceable in aligned sitting posture } \\
\hline \multicolumn{2}{|c|}{ Level 2} & \multicolumn{5}{|c|}{ Palceable in an aligned sitting posture but needs support } \\
\hline \multicolumn{2}{|c|}{ Level 3} & \multicolumn{5}{|c|}{ Able to maintain sitting when placed but cannot move } \\
\hline \multicolumn{2}{|c|}{ Level 4} & \multicolumn{5}{|c|}{ Able to move trunk slightly forwards-backwards over base without arching spine } \\
\hline \multicolumn{2}{|c|}{ Level 5} & \multicolumn{5}{|c|}{ Able to transfer weight laterally and regain posture (from one buttock to the other) } \\
\hline \multicolumn{2}{|c|}{ Level 6} & \multicolumn{5}{|c|}{ Able to move out position (i.e transfer weight onto feet and lift bottim of seat) } \\
\hline \multicolumn{2}{|c|}{ Level 7} & \multicolumn{5}{|c|}{ Able to move into and out of sitting position (i.e into standing and back) } \\
\hline
\end{tabular}

Table 6. Posture and Control Postural in Sitting Position Assessment (Parents interview)

\begin{tabular}{|c|c|c|c|c|c|}
\hline \multirow{2}{*}{ No } & \multirow{2}{*}{ Kemampuan } & \multicolumn{4}{|c|}{ Nilai } \\
\hline & & $\mathrm{D}$ & Ay & Ag & In \\
\hline \multirow[t]{3}{*}{1} & Head midline: & & & & \\
\hline & a. Stability movement and ability to keep head in midline position & 1 & 1 & 1 & 1 \\
\hline & $\begin{array}{l}\text { b. Ability and head movement skills to get harmony with rhythm of } \\
\text { music }\end{array}$ & 1 & 1 & 1 & 1 \\
\hline \multirow[t]{2}{*}{2} & Symmetrical Trunk & & & & \\
\hline & a. Back movement in symmetrical and arching/hunchback position & 1 & 1 & 0 & 1 \\
\hline \multirow[t]{2}{*}{3} & Body neutral & & & & \\
\hline & a. Shoulder movement & 1 & 1 & 1 & 1 \\
\hline \multirow[t]{4}{*}{4} & Pelvis neutral & & & & \\
\hline & a. Squat & 0 & 1 & 1 & 0 \\
\hline & b. Back movement in symmetrical and arching/hunchback position & 0 & 1 & 0 & 0 \\
\hline & c. Hip movement & 0 & 1 & 0 & 0 \\
\hline \multirow[t]{3}{*}{5} & Hips mid-position $\left(90^{\circ}\right)$ & & & & \\
\hline & a. Back symmetrical position & 0 & 1 & 0 & 0 \\
\hline & b. Back arching/hunchback position & 0 & 1 & 0 & 0 \\
\hline 6 & Knees mid-position $\left(90^{\circ}\right)$ & 0 & 1 & 1 & 0 \\
\hline \multirow[t]{2}{*}{7} & Legs separated and straight relative & & & & \\
\hline & a. Heel movement & 0 & 1 & 1 & 0 \\
\hline 8 & Arms resting by side & 0 & 1 & 1 & 1 \\
\hline \multirow[t]{5}{*}{9} & Weight evenly distributed & & & & \\
\hline & a. Body balance in sitting position & 0 & 1 & 0 & 1 \\
\hline & b. Move to transfer weight & 0 & 0 & 0 & 0 \\
\hline & c. Take objects by itbody & 0 & 1 & 0 & 0 \\
\hline & d. Leg bending & 0 & 0 & 0 & 0 \\
\hline \multirow[t]{2}{*}{10} & Feet mid-position/flat on floor & & & & \\
\hline & a. Feet extend in sitting position & 1 & 1 & 1 & 1 \\
\hline \multirow[t]{2}{*}{11} & Move out of sitting positions & 1 & 1 & 1 & 1 \\
\hline & Total & 6 & 16 & 9 & 8 \\
\hline
\end{tabular}


Table 7. GMFCS-E\&R

\begin{tabular}{|c|c|c|}
\hline Student & $\begin{array}{c}\text { GMFCS- } \\
\text { ER }\end{array}$ & Hasil Asesmen \\
\hline $\mathrm{D}$ & Level II & $\begin{array}{l}\text { - Children walk in most settings and climb stairs holding onto a railing. } \\
\text { - Experience difficulty walking long distances and balancing on uneven } \\
\text { terrain, inclines, in crowded areas or confined spaces. } \\
\text { - May walk with physical assistance, a handheld mobility device mobility } \\
\text { over long distances. } \\
\text { - Children have only minimal ability to perform gross motor skills such as } \\
\text { running and jumping. }\end{array}$ \\
\hline Ay & Level IV & $\begin{array}{l}\text { - Children use methods of mobility that require physical assistance or } \\
\text { powered mobility in most settings. } \\
\text { - Use powered mobility or a body support walker when positioned. } \\
\text { - At school, outdoors and in the community children are transported in a } \\
\text { manual wheelchair or use powered mobility }\end{array}$ \\
\hline $\mathrm{Ag}$ & Level V & $\begin{array}{l}\text { - Children are transported in a manual wheelchair in all settings. } \\
\text { - Children are limited in their ability to maintain antigravity head and } \\
\text { trunk postures and control leg and arm movements }\end{array}$ \\
\hline In & Level IV & $\begin{array}{l}\text { - Children use methods of mobility that require physical assistance or } \\
\text { powered mobility in most settings. } \\
\text { - Need support fot sitting position } \\
\text { - At school, outdoors and in the community children are transported in a } \\
\text { manual wheelchair or use powered mobility }\end{array}$ \\
\hline
\end{tabular}

Special programs in the curriculum 2013 called Body development and movement for children with physical handicapped, prepare services programs for motor development in body awareness contain the motion awareness of vertical axis, head control motion, limbs and extremity, awareness of the energy released in movement, motion of abdominal breathing and chest breathing, awareness of ability to move with purpose and movement harmony in gross motor coordination, fine motor coordination, eye and hand coordination, eye and foot coordination.

Motor development program for release tension contain passive movements in body parts that do not yet have the ability or strength of joint and muscles, active movements for optimizing muscle and joint movements, knowledge of muscle strength, joints and nerves, knowledge of spastic muscle and joint stiffness, balanced muscle to functional movements, ability to increases and reduce the strength of muscles, joints, nerves in limbs or extremities, sensomotor ability in spastic muscle, the ability of limbs experiencing difficulty moving to function optimally, the ability to regulate energy according to the release tension.

The postural and control posture insitting program contain postur of head midline, the body trunk simetrical, introduction of the hip center position for neutral pelvis, opening leg training straight relative to pelvis, arms resting- placement of arms next to torso, weight distributed evenly, hips mid-position, knee mid-position, feet mid position-flat on the floor, distribution of weight, exercise of arching the spine, training of back and forth positions in a sitting position, exercise transferring body weight to the edge and back upright (from one leg to the other), movement exercises from and to sitting position, practice sitting position to a standing position.

Children with cerebral palsy experiences stiffness or spastic, there will be needs for motor development training in body-awareness, release tension and posture control. Data obtained from 4 students of spastic cerebral palsy varied from the results of assessment and interview data, variations in posture control ability accordance with the theory where spastic cerebral palsy students as individuals had varying degrees of spasticity that affected their motor development, spastic cerebral palsy is characterized associated with hyperactive muscle stretch reflexes (deep tendon reflexes) and an increase in resistance to rapid muscle stretch. "(WHO, 2001). 
Data shows that variations in each assessment result that are neither high nor equally low, meaning that the ability of body-awareness is high, is not directed along with the ability to release tension and control posture in high score. These results indicate conformity with the definition of cerebral palsy by Gersh $(1998$, p. 2$)$ that cerebral palsy is a catch-up term for a variety of disorders that affects a child's ability to move and to maintain posture and balance. Bax et al (in Swaiman and Wu, 2012) also said cerebral palsy as a group of disorders of development of movement and posture, causing activity limitation, that are attributed to non-progressive disturbances that occur in developing fetal or infant brain.

The evolving definition of experts at this time does not only refer to motoric disorders but also includes other disorders that can occurs, by looking at the causes of heterogeneous motor disorders. The main disorders are movement and posture, which can accompany by sensory disorders, perception, cognition, communication, behavior, epilepsy, and musculoskeletal disorders (Rogers and Wong, 2012). Associated disorders such as seizures, cognitive, vision, hearing and behavior (Swaiman and $\mathrm{Wu}, 2012)$. In addition, Gersh (1998) also emphasizes the position and severity of injury in the brain will cause other problems. Variations in data obtained in spastic cerebral palsy students emphasize the preparation of service programs for suitability and adequate postural balance so as to improve the functional performance of cerebral palsy children (Nwaobi, 1987; Myhr and von Wendt, 1991; McClenaghan et al, 1992), performance improvement functionality is in line with the increased ability to maintain and control the posture (Tekin, et al, 2018; Elbasan, et al, 2018).

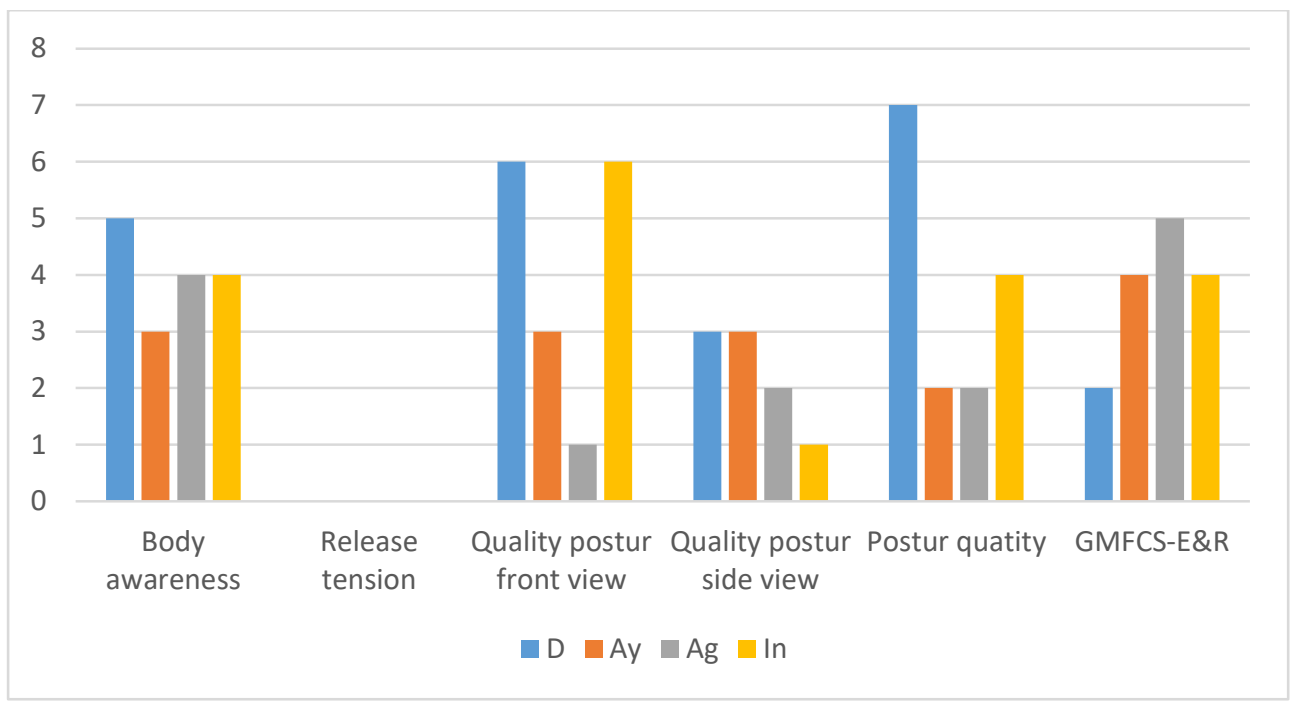

Figure 1. Asesment BARS, RTc, PPAS, GMFCS-R of 4 CP spastic student

\section{Conclusions}

Profile of 4 spastic cerebral palsy students from assessment and analysis the ability, existing problems and the needs of the child on body-awareness, release tension and control postur in sitting position in quality - quantity control, showing variations in achievement, this result shows data achievement ability is not prerequisite for each capability but becomes a single unit to achieve functional movements, service preparation programs to improve motor skills must be given together in body-awareness learning, tension release and posture control when preparing a service program. This is in accordance with the findings of Massion, 1994 and Hong 2002 which stated that motor function involves almost all activities in life, postural control, postural stability is a prerequisite for functional movement tasks, inability to control posture will have a significant impact on achieving its function (Hong, 2002 ; Shumway-Cook et all, 2012; Saether, 2013), body-awareness ability is a basic ability of a person to be able to achieve good quality functional movements. Body-awareness is a fundamental process for controlling actions (Murata and Ishida, 2007). 


\section{Acknowledgments}

Acknowledge to Special School of YPAC Bandung, all parents and student, also grant from Ministry of Research, Technology and Higher Education in 2018

\section{References}

Elbasan, B. Dkk. (2018). Effects of Neuromuscular Electrical Stimulation and Kinesio Taping Applications in Children with Cerebral Palsy on Postural Control and Sitting Balance. Journal of Back and Musculoskeletal Rehabilitation, 31, hlm. 49-55

Gersh, Elliot. (1998). What is cerebral palsy?. Dalam Elaine Geralis (Penyunting). Children with cerebral palsy, a parents guide (hlm.1-34). USA: Woodbine House.

Hong, C.S. (2002) Positioning for children with learning disabilities. British Journal of Therapy $\mathcal{E}$ Rehabilitation, 9, hlm. 443-446

Massion, J. (1994). Postural control system. Current opinion in neurobiology, 4, hlm. 877-887.

McClenaghan, B.A. Thombs, L. \& Milner M. (1992). Effects of seat-surface inclination on postural stability and function of the upper extremities of children with cerebral palsy. Developmental Medicine and Child Neurology, 34, hlm. 40-48.

Murata, A., Ishida, H. (2007). Representation of bodily self in the multimodal parieto-premotor network. Dalam Representation and brain (hlm. 151-176). Tokyo: Springer

Myhr, U. \& von Wendt, L. (1991). Improvement of functional sitting position for children with cerebral palsy. Developmental Medicine and Child Neurology, 33, hlm. 346-356.

Nwaobi O.M. (1987). Seating orientation and upper extremity function in children with cerebral palsy. Physical Therapy, 67, hlm.1209- 1212

Rogers, L dan Wong, E. (2012). Cerebral Palsy. [Online]. Diakses dari http://www.pathophys.org/cerebralpalsy/

Saether, R., Helbostad, J. L., Riphagen, I. I., \& Vik, T. (2013). Clinical tools to assess balance in children and adults with cerebral palsy: a systematic review. Developmental Medicine \& Child Neurology, 55, hlm. 988-999

Shumway-Cook A, Woollacott MH. (2012). Normal Postural Control. Dalam Motor Control: Translating Research Into Clinical Practice (hlm 161-194). Baltimore: Lippincott Williams \& Wilkins.

Swaiman, K.F dan Wu, Y.W. (2012). Cerebral palsy. Dalam Swaiman dkk (Penyunting). Swaimans pediatric neurology, principle and practice (hlm. 999-1008). China: Elsevier Inc.

Tekin, F. Dkk. (2018). Effectiveness of Neurodevelopmental Treatment (Bobath Concept) on Postural Control and Balance in Cerebral Palsied Children. Journal of Back and Musculoskeletal Rehabilitation, 31, hlm. 397-403

World Health Organization. (2001). ICD-11 for Mortality and Morbidity Statistics. [Online]. Diakses dari m/en\#/http\%3a\%2f\%2fid.who.int\%2ficd\%2fentity\%2f1426032265

https://icd.who.int/browse11/1- 